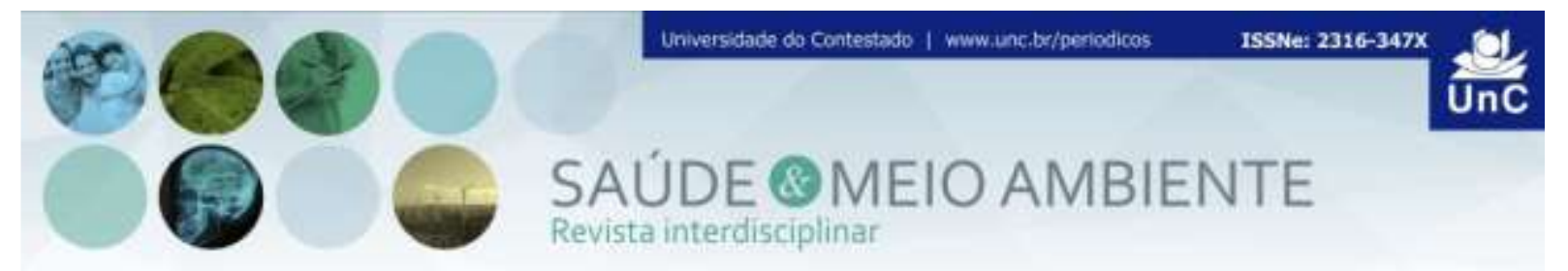

\title{
REFLEXÕES ACERCA DAS PERCEPÇÕES DOS PROFISSIONAIS RESIDENTES SOBRE UM PROGRAMA DE RESIDÊNCIA MULTIPROFISSIONAL EM SAÚDE DA FAMÍLIA
}

\section{REFLECTIONS ON THE PERCEPTIONS OF RESIDENT PROFESSIONALS ABOUT A MULTIPROFESSIONAL RESIDENCY PROGRAM IN FAMILY HEALTH}

Regina Pereira Jungles ${ }^{1}$

Bruna Lopes Martins ${ }^{2}$

Pamela Freitas Machado ${ }^{3}$

\begin{abstract}
RESUMO
Conforme o surgimento e desenvolvimento do Sistema Único de Saúde (SUS), através da Reforma Sanitária, se discute políticas públicas e a forma que se estabelece o cuidado em saúde. Evidenciando aqui a Atenção Primária como porta de entrada do SUS e ordenadora do cuidado. Assim também busca se refletir sobre a atuação dos profissionais e sua qualificação para desenvolverem atividades segundo os princípios do SUS. Com isso, as Residências Multiprofissionais em Saúde surgem como forma de educação permanente que objetiva qualificar a formação profissional. A partir disso, o estudo objetivou-se compreender as percepções e expectativas dos profissionais residentes de um Programa de Residência em Saúde da Família do Vale do Taquari. Tratou-se de um estudo qualitativo no qual foram realizadas uma entrevista através de formulário online com 12 profissionais das áreas de Enfermagem, Fisioterapia, Nutrição e Psicologia, que concluíram ou estão em processo de formação na residência em saúde da família. O método de análise foi baseado na metodologia de práticas discursivas de Mary Jane Paris Spink, a qual aborda sobre os sentidos e significados expressos no cotidiano dos serviços de saúde. Com isso percebeu-se que a residência é composta por alguns interlocutores, sendo de maior evidência tutor, preceptor e residente, sendo atribuído a cada um diferentes papéis e sentidos que são construídos no decorrer do processo. Ainda, a residência é um processo potente e positivo no contexto de formar profissionais para o SUS, sendo evidenciado nas falas dos residentes, porém apresenta diversos desafios no seu funcionamento e organização.
\end{abstract}

Palavras-chave: Residência multiprofissional em saúde. Atenção primária. Educação em saúde.

\footnotetext{
${ }^{1}$ Psicóloga. Universidade do Vale do Taquari. Rio Grande do Sul. Brasil. E-mail: regina.jungles@universo.univates.br

2Psicóloga. Universidade do Vale do Taquari. Rio Grande do Sul. Brasil. E-mail: bruna.martins@univates.br

${ }^{3}$ Doutorado em Psicologia pela Pontifícia Universidade Católica do Rio Grande do Sul. Professor Assistente da Universidade do Vale do Taquari. Rio Grande do Sul. Brasil. E-mail: pamela.machado@univates.br
} 


\begin{abstract}
As the emergence and development of the Unified Health System (SUS), through Health Reform, public policies and the way health care is established are discussed. Evidencing Primary Care here as a gateway to the SUS and ordering care. Thus, it also seeks to reflect on the performance of professionals and their qualification to develop activities according to SUS principles. With that, Multiprofessional Residencies in Health appear as a form of permanent education that aims to qualify professional training. Based on this, the study aimed to understand the perceptions and expectations of professionals resident in a Family Health Residency Program in Vale do Taquari. It was a qualitative study in which an interview was conducted through an online form with 12 professionals in the areas of Nursing, Physiotherapy, Nutrition and Psychology, who completed or are in the process of training in the family health residency. The method of analysis was based on the methodology of discursive practices by Mary Jane Paris Spink, which addresses the senses and meanings expressed in everyday health services. With that, it was realized that the residency is composed of some interlocutors, with greater evidence being tutor, preceptor and resident, with each one being assigned different roles and meanings that are constructed during the process. Still, residency is a powerful and positive process in the context of training professionals for the SUS, being evidenced in the residents' statements, but it presents several challenges in its functioning and organization.
\end{abstract}

Keywords: Multiprofessional health residency. Primary attention. Health education.

\title{
INTRODUÇÃO
}

Atualmente, discute-se muito sobre o cuidado em saúde e sobre a formação de profissionais para trabalhar na área. As discussões teóricas e práticas enfatizam isso e a importância de se pensar sobre. Todas as modificações a respeito da saúde são sempre pensadas de forma a proporcionar o melhor cuidado para a população, também as legislações vêm para caracterizar como devem ser os serviços prestados e qualificar a atuação dos profissionais que ali estão inseridos. Com isso, pensando nos profissionais, na qualificação desses, no desenvolvimento de habilidades e competências para a atuação junto ao Sistema Único de Saúde (SUS) é que se pensa na educação permanente. Essa se configura como uma proposta de aprendizagem no trabalho, na qual o aprender e o ensinar se incorporam ao cotidiano, ainda se baseia em uma forma de aprendizagem significativa e na possibilidade de transformar as práticas profissionais ${ }^{1}$. Pensando nisso e na importância de buscar aprendizagem e qualificação profissional, o Ministério da Saúde criou em 2004 a Política Nacional de Educação Permanente em Saúde (PNEPS), sendo que a mesma vem sendo modificada conforme o passar dos anos e as mudanças do contexto ${ }^{2}$.

Ainda, antes disso se começou a pensar a formação dos profissionais de uma forma diferenciada com o surgimento das residências multiprofissionais em saúde (RMS), visto a importância de se repensar a prática profissional, assim como se vinha pensando a construção e desenvolvimento do SUS. As RMS são consideradas uma 
forma de educação permanente, onde se busca uma aprendizagem no cotidiano, agregando ainda a aprendizagem acadêmica enquanto título de especialização. Com tudo isso, ao iniciar o Programa de Residência Multiprofissional em Saúde da Família (PRMSF) no Vale do Taquari se percebeu a oportunidade de estar qualificando, através da inserção dos residentes, tanto a rede de saúde como também os próprios profissionais inseridos no programa. Sendo assim, o trabalho buscou proporcionar uma forma de compreender o entendimento e a percepção do programa, refletindo sobre o papel formativo e seus interlocutores, através do olhar dos residentes.

\section{MÉTODO}

O presente estudo tratou-se de uma pesquisa qualitativa, que propôs estudar o universo de sentidos, significados, motivos, desejos, valores e atitudes, relacionados aos residentes e sua percepção acerca do programa de residência escolhido. Para a coleta de dados foi elaborado um questionário através de um formulário online e o convite realizado através de contato por e-mail. Convidou-se a participar 23 profissionais das áreas de Enfermagem, Fisioterapia, Nutrição e Psicologia, foi estipulado um prazo de um mês para resposta, sendo assim, após o término do período, houve um total de 12 respondentes.

Sobre o questionário, Pinheiro 3 escreve que para responder perguntas os sujeitos recorrem às informações que circulam pelo seu meio que são processadas a partir de suas experiências. As mesmas são ressignificadas e são produzidos sentidos para a pessoa, assim se estabelece a resposta para a pergunta feita. O questionário foi dividido em três etapas: Termo de Consentimento Livre e Esclarecido que teve o aceite mediante a confirmação de pergunta obrigatória no formulário. Questionário sociodemográfico, com perguntas objetivas e fechadas. E por fim questionário sobre a residência com seis perguntas subjetivas e dissertativas, as quais tratavam sobre as percepções dos residentes a respeito do processo formativo da residência, contribuições, desafios e sobre os papéis desenvolvidos pelos interlocutores.

Para analisar os dados coletados trabalhou-se com a metodologia de práticas discursivas de Mary Jane Paris Spink ${ }^{4,5}$, a qual aborda sobre os sentidos e significados expressos no cotidiano dos serviços de saúde. Sendo assim buscou-se olhar para esses aspectos a partir das respostas dos participantes da seguinte forma: realizouse uma leitura flutuante das respostas dos questionários, permitindo uma compreensão inicial da situação dialógica e do uso que estava sendo feito do formulário de pesquisa. Também entender a linha de argumento, linha esta que está obviamente amarrada às versões do eu que estão sendo veiculadas. Em segundo momento foi realizada a elaboração de mapas de associação de ideias, construção de temáticas e repertórios interpretativos, identificação de quem são os interlocutores e a elaboração de diferentes categorias sobre as narrativas, sendo elas, os interlocutores: tornar-se tutor, preceptor e residente e o processo formativo: teórico e prático. Isto permitiu apreender de forma bastante direta as representações presentes e as narrativas (respostas) nas quais estas representações adquirem sentido e 
significação. E por fim, análise das respostas (narrativas) em busca da produção de sentido, que é baseada nos indicadores previamente descritos. A pesquisa foi submetida ao comitê de ética, sendo aprovada através do protocolo CAAE: 32675320.7 .0000 .5310 .

\section{RESULTADOS E DISCUSSÃO}

A Residência Multiprofissional em Saúde da Família

Para analisar os resultados é preciso pensar no contexto em que estão inseridos os interlocutores, ou seja, a residência multiprofissional em saúde. As RMS são regulamentadas no ano de 2005 através da Lei $n^{\circ} 11.129$, sendo criada, no Ministério da Educação, a Comissão Nacional de Residência Multiprofissional em Saúde ${ }^{6}$.

Domingos, Nunes e Carvalho ${ }^{7}$ afirmam que através dos programas de residência é possível formar profissionais que atuem na gestão, na atenção primária, no cuidado das pessoas e comunidade, fortalecendo e desenvolvendo o trabalho em equipe e interdisciplinar. Ainda, possibilita uma forma de reorientação do modelo assistencial dos serviços de saúde, buscando através da educação permanente instrumentalizar os profissionais que estarão atuando nos serviços públicos de saúde ${ }^{8}$.

Iniciar um processo formativo em uma residência multiprofissional diz de pensar na educação permanente em saúde e qualificação para atuação profissional nas redes de saúde, sendo o ensino-serviço o pilar da mesma, pois visa essa qualidade da assistência, a própria formação profissional e satisfação dos trabalhadores dos serviços ${ }^{9}$.

Com todo o contexto das residências mencionado, o PRMSF, surge em 2016, sendo que a primeira turma de residentes iniciou em 2017. A figura 1 representa a organização do processo formativo segundo o projeto pedagógico do PRMSF e regimento interno. 
Figura 1 - Organização do processo formativo segundo o projeto pedagógico do PRMSF e regimento interno

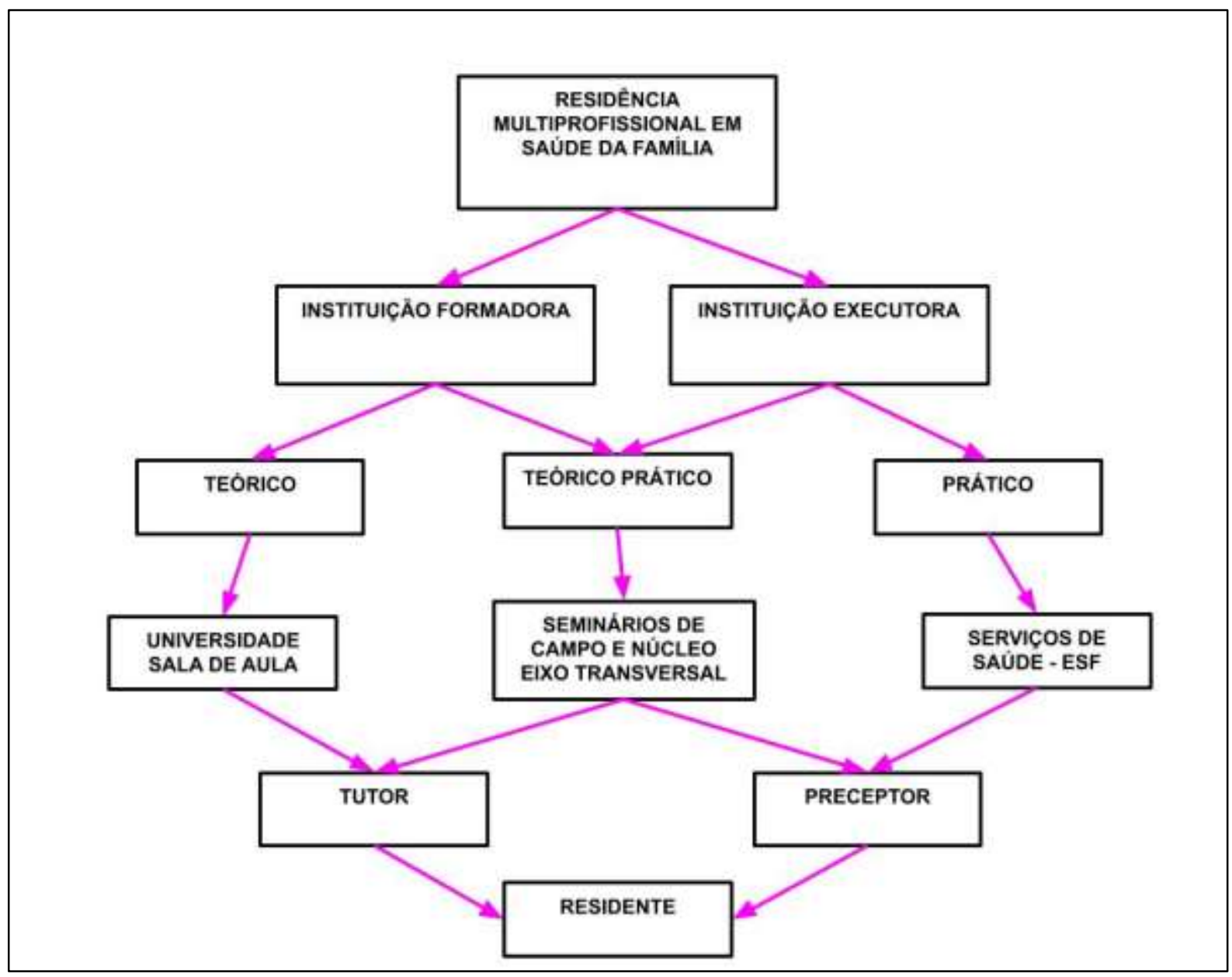

Fonte: Produção das autoras

A partir da perspectiva interdisciplinar, se pretende construir uma prática diferenciada, possibilitando novas formas do profissional vivenciar os serviços, buscando uma visão mais integradora dos usuários e da rede. A atuação dos residentes se dá na atenção primária, vivenciando ainda eixos de gestão e das vigilâncias em saúde. Os objetivos do programa visam, "formar profissionais de saúde especialistas na promoção do cuidado em saúde, focando na atenção primária e no enfrentamento da tríplice epidemia" ${ }^{10}$. O programa contemplou um total de 24 residentes, sendo três turmas, duas formadas e a terceira encerrando o processo.

Os interlocutores: tornar-se tutor, preceptor e residente

Para compreender os envolvidos, é importante ressaltar algumas características dos participantes. Dos 12 respondentes $8(66,7 \%)$ encontram-se na faixa etária dos 25-30 anos de idade, já $4(33,3 \%)$ estão acima dos 30 anos, a 
informação de idade pode também se relacionar diretamente com outro dado encontrado, sendo o tempo de formação. Sobre isso, $7(58,3 \%)$ têm menos de um ano de formação, $1(8,3 \%)$ tem até dois anos e por fim, $4(33,3 \%)$ têm mais de três anos. Tais dados podem se relacionar devido a residência por vezes ser uma especialização buscada, em grande maioria por recém formados, que buscam aprofundar e ampliar conhecimentos que a graduação não consegue cobrir ${ }^{11}$.

Assim, voltamos a pensar nos diferentes envolvidos no processo, tutor, preceptor e residente, conforme a figura 2 é possível identificar algumas atribuições dos diferentes interlocutores da residência e seus papéis. Compreende-se esses como os tutores, preceptores e residentes, sendo esses últimos os respondentes da pesquisa.

Figura 2 - Atribuições dos diferentes interlocutores da residência e seus papéis

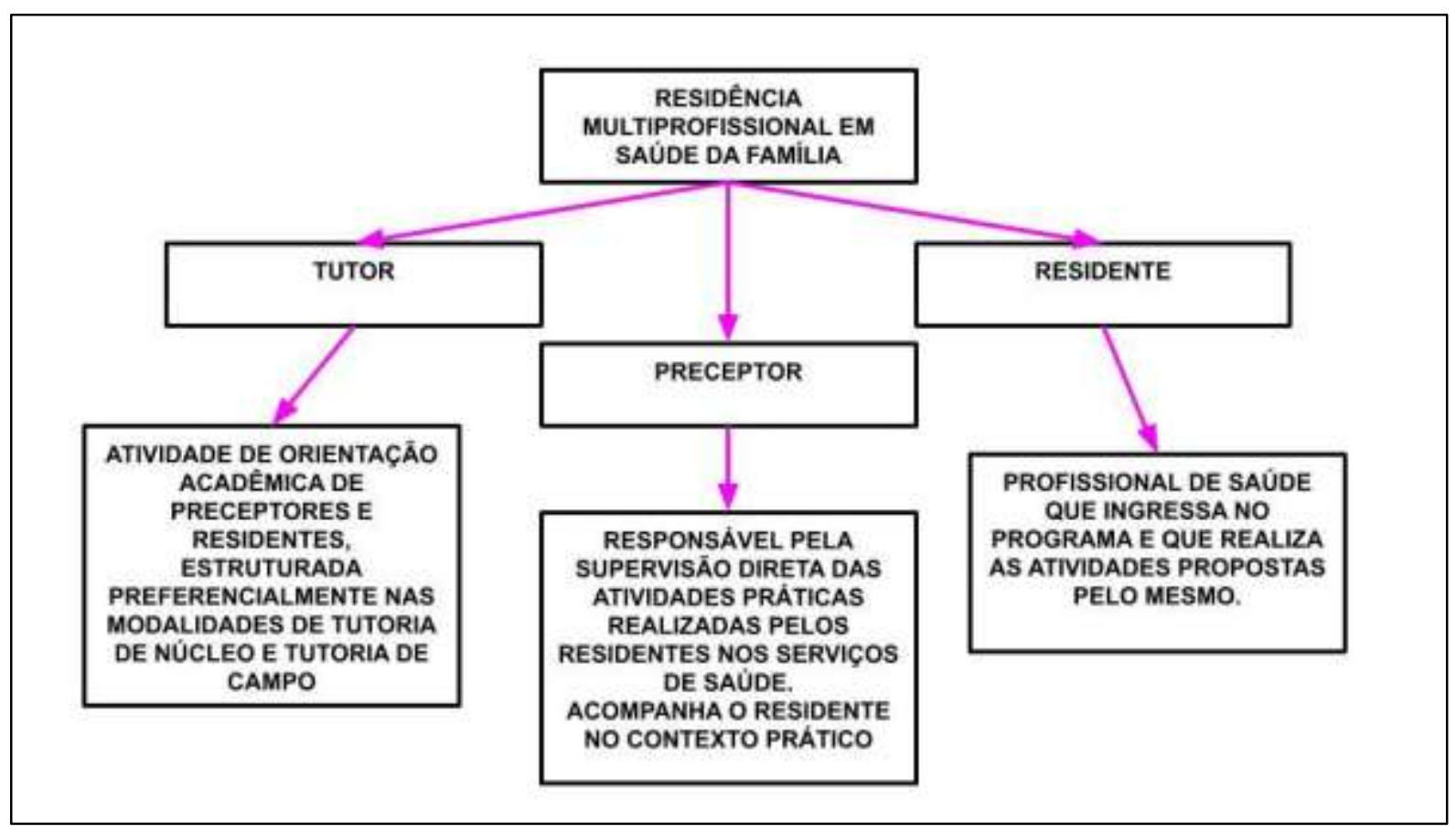

Fonte: Produção das autoras

\section{Os tutores}

Para começar a pensar quem é o tutor, é preciso pensar sobre o conceito atribuído ao mesmo. Primeiramente, no dicionário, tutor pode ser entendido como "aquele que tutora, que exerce tutoria, jurídica ou não, indivíduo que protege, ampara e defende alguém ou algo mais frágil; guardião"12. Ainda, pensando no mesmo conceito o tutor pode ser visto como tendo a função de supervisão docenteassistencial no campo de aprendizagem profissional na área da saúde, desenvolvendo papel de orientadores de referência para os profissionais ou 
estudantes, devendo pertencer à equipe local de assistência e estar diariamente presente nos ambientes onde se desenvolvem as aprendizagens em serviço ${ }^{13}$.

No caso do PRMSF o tutor está vinculado exclusivamente com a instituição formadora do programa, tendo como atribuições as mencionadas na figura 2, conforme regimento interno. Tais percepções são evidenciadas no retorno dos residentes ao falarem sobre os papéis do tutor:

Tutor: Guiar, facilitar o processo de ensino-aprendizagem (R3)

Tutor: Trazer embasamento teórico e propor reflexões (R7)

Os docentes seriam a ponte com a instituição formadora, atuando na supervisão docente, mas integrando os cenários de prática e teoria, buscando uma articulação com os preceptores a fim de pensar o planejamento das atividades e o processo de formação na residência. (R8)

O tutor deve dar suporte aos preceptores e residentes (R9)

O tutor tem o papel de acompanhar a trajetória do residente, orientando e sugerindo formas de superar os desafios e ampliar as questões da coletividade. (R11)

Se entende o papel do tutor como professor, o que guia os estudos e processo de aprendizagem, é aquele que orienta, ajuda na busca de conhecimento e tem também papel importante como avaliador ${ }^{14}$. E, ainda, o tutor também é entendido como alguém para articular com preceptores e conduzir em conjunto o processo teórico-prático, aproximando-se também do campo de atuação da residência.

A partir dessa compreensão do que entende-se do papel de tutor pelos residentes e também o que se propõe a literatura é possível pensar que houveram divergências em alguns aspectos, como pode ser visto na fala de R6, parece que em cada núcleo vivíamos experiências e modos de ver estes papéis de modos diferentes. O entendimento do papel do tutor no campo teórico é o principal sentido atribuído, porém no quesito da aproximação com a prática, essa não se destaca, como complementa R6, a teoria pouco acompanhou a prática, foi bastante superficial, sem muita ligação.

O tutor é muito importante no processo formativo da residência, principalmente no quesito teórico e teórico-prático, eles devem buscar mediar relações, facilitar a entrada nos territórios, educadores imersos em um processo formativo complexo ${ }^{15}$.

\section{Os preceptores}

$\mathrm{Na}$ continuidade de se compreender os interlocutores do processo da residência, chega-se ao preceptor. O papel desse pode ser compreendido como "aquele que dá preceitos ou instruções, ensinando e compartilhando experiências, para melhorar a competência clínica e ajudar o residente a se adaptar ao exercício da profissão"16. É o profissional que está no campo prático e que acolhe o residente e o auxilia no desenvolvimento da prática. Os papéis de preceptores e tutores podem se 
atravessar e se complementarem nos processos formativos, ambos têm a atribuição de guiar e orientar o residente.

No PRMSF, a preceptoria é exercida de diferentes formas, contemplando a de núcleo e a de campo, sendo nessa primeira o preceptor da mesma profissão do residente e na segunda profissional que está no mesmo local de atuação do residente, não sendo necessariamente do mesmo núcleo, nos retornos dos residentes pouco apareceu essa divisão, sendo a preceptoria definida da seguinte forma:

Profissional contratado ou concursado do serviço de atuação do residente. (R1)

Preceptor - orientar às práticas de campo, com discussões de caso embasadas teoricamente, mas também através do compartilhar de suas experiências profissionais. (R4)

Preceptor: auxiliar e orientar o residente no campo de prática. (R7)

Os preceptores seriam os profissionais que atuam nos cenários de práticas e que seriam responsáveis em auxiliar a(o) residente a pensar sua prática profissional, orientar o planejamento das suas atividades e atuação no espaço que está inserido, favorecendo a construção de um conhecimento teórico-prático.(R8)

Tais apontamentos corroboram com as ideias já mencionadas na literatura e é reforçada por Souza e Ferreira ${ }^{17}$ que descrevem o preceptor como o profissional que participa do processo formativo ao integrar a prática com o conhecimento científico, tornando a vivência prática um espaço de experiências de aprendizagem.

Porém, se percebe através da percepção dos residentes uma dificuldade da compreensão dos preceptores sobre a residência e o funcionamento da mesma, inclusive sobre seu papel, como apresentada na fala de R4 "Os preceptores locais têm pouco ou nenhuma aproximação com a residência, não compreendendo o papel da residente, o que se perpetua nas equipes". Tal atravessamento representa uma dificuldade encontrada no percurso e que interfere no processo formativo dialogado na próxima categoria.

Os residentes

Para compreender quem são os residentes é necessário identificar as motivações que auxiliaram que o profissional escolhesse um programa de residência multiprofissional em saúde, no caso com ênfase em saúde da família. Dos respondentes a grande maioria, como mencionado anteriormente, buscou a residência como uma forma de aprofundar questões relacionadas a graduação, principalmente no que diz respeito à atuação profissional na atenção primária, como podemos observar em algumas falas dos participantes:

Como minha graduação foi voltada às doenças, escolhi essa residência para ter experiência em promoção da saúde da população, participar de programas, campanhas, serviços e intervenções criadas com o objetivo de 
melhorar as condições de saúde através da propagação de estilos de vida saudáveis e de tratamentos para doenças, também (R3)

[...] A opção em atuar com saúde da família surgiu do interesse de atuar na atenção básica, nível de cuidado que não tive aproximação durante a graduação (R4)

As expectativas iniciais eram de aprofundar todas as questões da atenção básica e entender como funciona e como posso contribuir frente a saúde da família (R11)

As ideias de Morais e Souza ${ }^{6}$ evidenciam que os profissionais podem atuar de diferentes formas na residência, atentando não somente à recuperação e reabilitação do paciente, mas também à educação em saúde como forma de promoção e prevenção, junto com a ideia da política de educação permanente.

Para o PRMSF, o residente é o profissional da saúde que ingressa no programa e tem como objetivo desenvolver algumas habilidades e competências previstas para a formação de especialista. Para os próprios residentes o seu papel é compreendido como:

O Residente é um integrante provisório na equipe de saúde. Acredito que a sua função seja facilitar a integração entre os serviços, promover a interdisciplinaridade e troca de saberes, participar do gerenciamento e da promoção do cuidado. (R2)

Residente: atuar em campo e com base nos conhecimentos teóricos e práticos discutir com os demais envolvidos, refletir, propor mudanças e auxiliar nessa transformação. (R7)

O residente, por exemplo, me parece um profissional "novo" (novo no sentido de ser alguém que vem de fora de uma rede que já existe, com sua formação, seu conhecimento, seus valores e opiniões), mas é alguém que está sendo inserido em um contexto diferente, onde estará aberto a aprender. Mas também não deixa de ensinar, de alguma forma, quando compartilhar seus conhecimentos nos espaços onde está inserido. (R12)

A partir da compreensão dos próprios residentes é possível entender esse profissional como alguém que traz novas ideias e um novo olhar para uma equipe de saúde, visando o cuidado dos usuários e também a satisfação da equipe. Assim, como Silva et al. ${ }^{18}$ mencionam, é através da residência que se pode trazer a oportunidade de novos conhecimentos acerca de outras áreas, fazendo com que profissões diferentes se auxiliem e se complementem.

Refletindo ainda sobre o papel do residente $\mathrm{R} 4$ relata:

Fica a cargo do residente a todo tempo marcar esse lugar, mas como estamos em processo de aprendizagem também muito se confunde e acaba prejudicando a papel formativo da residência, tornando o residente por vezes mão de obra para a demanda que se apresenta.

Os residentes não são profissionais com vínculos efetivos junto aos serviços de saúde. As dificuldades encontradas na prática influenciam no processo formativo, como por exemplo a utilização do residente em substituição a uma categoria profissional insuficiente no serviço ${ }^{19}$. Tal apontamento reflete uma grande discussão de espaços coletivos de residentes e do pensar o processo formativo, a dificuldade de compreensão do que é a residência e a ideia de entender o residente apenas como uma mão de obra a mais para a demanda que se apresenta. 
Importante ainda refletir sobre a fala de R8 que diz: Não são lugares estáticos e prontos, estão a todo o tempo em construção. [...] o papel do residente é atuar numa perspectiva de cuidado integral, compreendendo a residência enquanto um processo de formação no e para o SUS. A compreensão desse papel como o de pensar um profissional em formação para o SUS é o que se compreende de maneira geral o processo formativo da residência. A realidade de ensino e assistência vivenciada pelos residentes contribui agregando conhecimento no processo de formação profissional dos residentes para o SUS ${ }^{18}$. E ainda Silva ${ }^{20}$ finaliza que pensar esse papel e todo o processo de formação é investir em formar "profissionais de saúde sintonizados com a defesa dos princípios basilares do tão ameaçado Sistema Único de Saúde brasileiro" (p. 201).

O processo formativo da residência: teoria e prática

As RMS vêm com o intuito de formar profissionais para atuação no SUS, como mencionado, visando seus princípios, o trabalho em equipe e qualificação da assistência. Depois de compreender os papéis dos interlocutores e os sentidos atribuídos a cada um, é preciso refletir sobre o processo formativo do PRMSF, visando também compreender os sentidos atribuídos a esse espaço. Conforme a figura 3 , o processo formativo da residência é dividido em três aspectos formativos principais, teórico, teórico-prático e prático.

Figura 3 - Processo formativo da residência

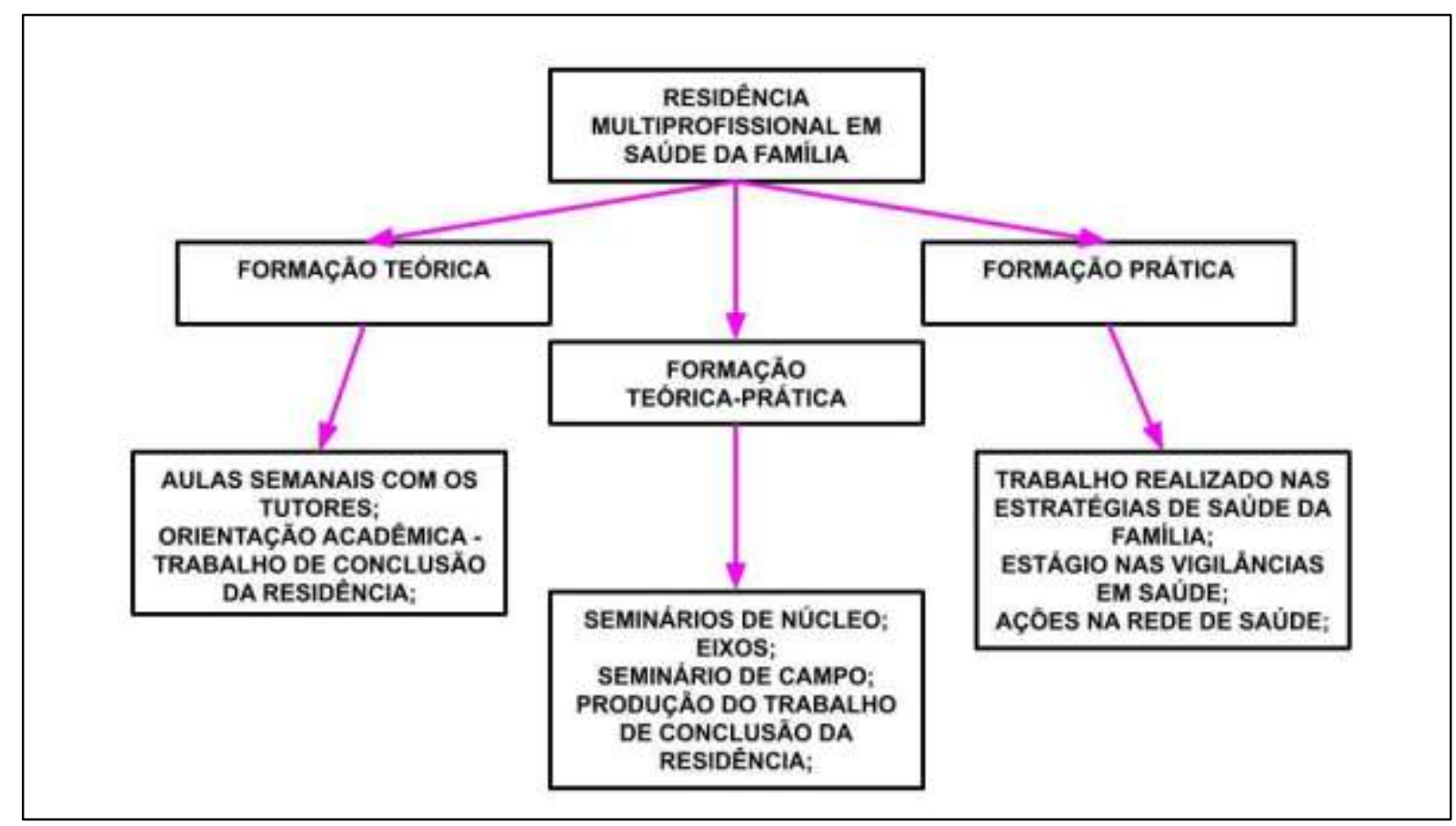

Fonte: Produção das autoras 
Pensar a formação teórica em um processo de residência diz de refletir sobre a proposta da educação permanente, que aborda a ideia de produzir conhecimento a partir da interlocução entre educação e trabalho. Trata-se de uma formação e desenvolvimento de profissionais de saúde de modo descentralizado, ascendente e transdisciplinar, desenvolvendo reflexividade das práticas e problematização da realidade $^{18}$.

A teoria é extremamente importante para o contexto da prática, há a necessidade de compreensão dos conceitos para aplicá-los, alguns apontamentos dos residentes sobre a formação teórica do PRMSF apresentam indagações sobre o processo:

\begin{abstract}
Em relação aos conteúdos passados nas aulas teóricas, penso que em alguns momentos foi bem vago, com discussões que não tinham muito sentido e desnecessárias. Porém, algumas aulas foram excelentes para o processo formativo. Nos deram a real noção de como a atenção básica funciona. (R1)

Quanto ao campo teórico, observo que ele poderia ser melhor estruturado e aprofundado. Discutíamos muito a prática, o que era extremamente importante, mas por vezes, senti falta de um amparo teórico mais consistente. Pudemos ao longo do processo repensar a estrutura das aulas e considero muito positiva essa abertura. (R8)
\end{abstract}

Conforme o relato de R1 e R8, há alguns descontentamentos com os espaços teóricos formativos, principalmente no que diz respeito a parte teórica como conceito, mas ao mesmo tempo se coloca a problematização do momento e também tentativas de solução das incoerências. Repensar o processo formativo também diz respeito de uma atuação ativa dos residentes frente a residência.

A relação estabelecida entre residentes e tutores permanece confusa nos relatos, sem muito entendimento geral dos papéis (como já visto na categoria anterior). Então, ao mesmo tempo que se tem a tutoria para pensar a relação entre a teoria e prática, e que pouco foi evidenciada pelos residentes, o tutor como professor do espaço de aulas teóricas é qualificado como positivo, porém também sem muito aproveitamento como R12 evidencia tal constatação em sua fala:

\footnotetext{
Sobre as aulas teóricas, acho que eram muito bem organizadas quanto a frequência, espaço/estrutura física, comparando com outros programas de residência, lembro que o nosso era um dos únicos que tinha cronogramas de aulas bem elaborados, com professores qualificados, e dentro de uma instituição de ensino, o que é muito positivo e produtivo. No entanto, talvez pelo fato de ser um programa novo, sinto que faltou um pouco de aproveitamento desse importante espaço das aulas. Senti falta de uma melhor estruturação dos conteúdos, de iniciar, por exemplo, discutindo as políticas e normas de funcionamento dos serviços, por exemplo, para que, junto da prática, tivéssemos a fundamentação, legislação e teorias orientadoras.
}

Outro ponto que emergiu também dos sentidos atribuídos diz de uma forma diferente de pensar a formação teórica, enquanto alguns atribuem esse espaço como pouco agregador, outro residente coloca o contraponto de também um não aproveitamento desse espaço por parte dos colegas: 
[...] Por outro lado, penso que os residentes pouco souberam aproveitar os momentos teóricos, havia pouco engajamento/engajamento de poucos nas discussões e na tentativa de aprofundarmos nosso conhecimento (R9)

Todas as articulações apresentadas provocam reflexão sobre a residência, alguns autores apresentam dificuldades como essas, ao pensar o processo formativo, muitas envolvendo a relação entre os diferentes interlocutores, onde inicialmente se percebe um engajamento coletivo que conforme o passar do tempo e as adversidades geram desânimo e desmotivação ${ }^{21}$. No caso do PRMSF, um dos aspectos desmotivacionais pode estar relacionado com o término da residência como mencionado por R4: "[...]Talvez um fator prejudicial e que desmotivou todos os que estão envolvidos com a Residência é a previsão do seu término na atual turma".

Ainda, na discussão sobre a formação teórica, Silva e Moreira ${ }^{19}$ mencionam que:

É preciso que a formação no contexto da residência esteja articulada com as demandas inerentes à prática, buscando estratégias para que as atividades teóricas estejam em consonância com a realidade que o residente vivencia, gerando maior investimento na integração ensino-serviço (p. 162).

$\mathrm{Na}$ continuidade, outro aspecto formativo é o teórico-prático, que no caso do PRMSF se dava através de diversos contextos como demonstrado anteriormente na figura 3. Para os residentes esses espaços são muito importantes e essenciais, mas que também pouco foram aproveitados pelos interlocutores:

Também haviam espaços teórico-práticos muito importantes (eixos, núcleos e seminários) que, da mesma forma, eram espaços primordiais de formação mas que, talvez por não se ter clareza sobre o projeto pedagógico, ou uma estrutura, com objetivos mais delimitados e claros sobre a utilização desses espaços, acabaram muitas vezes não sendo aproveitados da melhor maneira. (R12)

Toda a compreensão sobre o processo formativo da residência e sua organização perpassa a construção do projeto pedagógico, regimento interno e legislações organizativas e instrutoras das residências. O grupo de residentes que participaram do estudo, em grande maioria, responderam que conhecem o projeto pedagógico e ainda acrescentam:

Algumas informações foram dadas no início da residência e houve movimento por parte das(os) residentes em compreender melhor este projeto pedagógico que em muitos momentos causava dúvidas. A partir desses questionamentos também ocorreu a construção do Regimento do programa através de uma iniciativa das(os) residentes (R8)

Através dessa compreensão é identificável que os residentes buscaram conhecer o projeto e também compor um processo reflexivo sobre o mesmo, causando indagações e mudanças. Mas outro ponto observado foi que a iniciativa de tais ações foram dos residentes, sem muita atitude observada por parte dos demais envolvidos na residência como descreve o colega R12, que foi quem mencionou não conhecer o projeto pedagógico, "não lembro de termos lido e estudado esse projeto de forma aprofundada em nenhum momento da residência." 
Todos os aspectos mencionados dizem sobre outro desafio encontrado no contexto do processo formativo, a comunicação. R4 evidencia "falhas de comunicação entre equipes do campo, gestão municipal, residência (tutores, coordenação, secretaria e preceptores) e residentes". Para Silva et al ${ }^{18}$ é necessário constantemente discutir a operacionalidade e funcionamento, para que se possa viabilizar de forma efetiva, essa formação para as áreas de saúde. positivo:

$\mathrm{E}$, ao se falar sobre o aspecto prático da residência o olhar é amplamente

\begin{abstract}
A parte prática da residência é muito rica. Nos dá um panorama de como a atenção básica funciona e nos instiga a criar novas formas de cuidado a população. (R1)

Embora as dificuldades existam, observo que o processo da residência permitiu que eu transitasse por diferentes espaços de cuidado, me deparasse com situações diversas e buscasse soluções para as demandas que surgiram, o que, inevitavelmente, contribuiu para a construção de diversas competências. (R8)

A residência foi uma excelente oportunidade significativa de aprendizado e contato com profissionais de diferentes áreas da saúde, através desta experiência percebi que consegui assumir uma nova conduta na prática profissional, adquirindo na assistência aos usuários um caráter mais humanizado e abrangente proporcionado através do compartilhamento efetivo dos conhecimentos específicos de cada área e a participação direta nas atividades de saúde. (R10)
\end{abstract}

De maneira geral a formação prática, o ensino em serviço é extremamente potente e enriquecedor. É uma formação que tem comprometimento com a geração de trabalhadores de saúde implicados com os princípios do SUS. É através dessa formação prática que é possível desenvolver relações interprofissionais visando a prática colaborativa centrada no paciente, o cuidado integrado, assegurando o tratamento consoante à realidade dos profissionais, da comunidade, da família e do paciente ${ }^{22}$. Ainda, esse tipo de formação permite uma maior proximidade com o território, tal conceito é de extrema importância no trabalho do SUS, diz de uma noção espacial que contempla o local e as relações de poder, conexões e interlocuções que funcionam ali23. Para o R11, tornou-se significativo estar no território e problematizar o trabalho vinculado a ele, como menciona: Viver junto da equipe aquela realidade do território e poder atuar sobre ele, com o privilégio de estar aprendendo, é uma oportunidade única (R11). Estar no território e trabalhar junto às equipes de saúde qualifica a formação, de modo a favorecer também intervenções capazes de se aproximar das necessidades da população na qual o profissional está inserido ${ }^{7}$.

Por fim, R9 evidencia que:

No seu potencial político, a residência como um todo é uma força de transformação da rede e tentativa de efetivação do SUS, a residência vem para reforçar ou inserir os profissionais residentes em uma formação/atuação para o SUS (que podem não ter tido na graduação), mas o residente não é um agente passivo, que somente recebe intervenções, ele também já atua e se experimenta nesse local de quem faz políticas de saúde. (R9) 
Com isso, para o SUS, a residência através da integração entre o trabalho e a educação é essencial, pois busca melhorar a qualidade da assistência prestada à população e de incentivar e qualificar a educação profissional para o SUS.

E ainda R9 propõe pensar que:

olhar e avaliar os cenários de prática e teóricos não pode ser feito se olharmos somente para uma das pontas, éramos vários envolvidos nesse processo e o aproveitamento dele depende de todos nós.(R9)

Com tal fala é possível refletir novamente sobre o papel de cada interlocutor na formação da residência e os sentidos atribuídos individualmente e coletivamente. A residência não é estática, ela é construída a partir das experiências dos envolvidos, buscando a formação de profissionais críticos, reflexivos que propõem ações e estratégias para a melhoria na qualificação profissional e no cuidado em saúde nos cenários de práticas.

\section{CONCLUSÃO}

O PRMSF formou/formará um total de 24 profissionais especialistas em saúde da família e que, de uma maneira geral, os participantes da pesquisa consideraram esse processo positivo para sua formação e atuação profissional. O PRMSF teve grande influência na construção e consolidação do perfil profissional de seus residentes, pois, conforme os relatos possibilitou uma atualização e compreensão de pensar o SUS e funcionamento do mesmo. Entende-se também que as RMS agregam conhecimento e aprofundam conceitos que, por vezes, pouco se abordou nas diversas graduações de saúde.

Um dos aspectos importantes é o de perceber a residência como uma formação para o SUS, sendo parte dele. Fica evidente no decorrer do trabalho o diferencial que se propõe as RMS, ao trabalhar vinculados ao serviço de referência dos usuários e território. Tais aspectos acrescentam na formação e qualificação dos profissionais residentes, podendo ser observado nas falas e também no decorrer do processo dos dois anos de RMS.

Ainda foi possível identificar os principais desafios e aspectos a melhorar do PRMSF, sendo identificados pelos residentes a comunicação entre os interlocutores como principal ponto. No decorrer da residência enfatizou-se a necessidade de se repensar a comunicação e elaborar estratégias para melhorá-la, como tentativa de se utilizar e aproveitar mais espaços coletivos teóricos-práticos. Mesmo com diversos desafios, pensar as RMS de forma reflexiva pode provocar novas formas de atualização e de se pensar a formação do profissional, sendo considerada um dispositivo capaz de provocar melhorias nesse processo pois ao ingressar na residência os profissionais puderam trabalhar engajados em um conceito de saúde ampliado, baseado nos princípios do SUS. 


\section{REFERÊNCIAS}

1. Bernardes A. Trabalho, Educação e Qualificação - Política Nacional de Educação Permanente (PNEPS). Ministério da Saúde, Brasília, DF [Internet]. 26 de jun. 2017 [acesso em 2020 out 30]. Disponível em: http://www.saude.gov.br/trabalhoeducacao-e-qualificacao/gestao-da-educacao/qualificacao-profissional/40695politica-nacional-de-educacao-permanente-pneps.

2. Brasil. Ministério da Saúde. Política Nacional de Educação Permanente em Saúde: o que se tem produzido para o seu fortalecimento?/Ministério da Saúde, Secretaria de Gestão do Trabalho e da Educação na Saúde, Departamento de Gestão da Educação na Saúde - 1. ed. rev. - Brasília : Ministério da Saúde [Internet]. 2018 [acesso em 2020 out 30]. Disponível em:

http://bvsms.saude.gov.br/bvs/publicacoes/politica_nacional_educacao_permanen te_saude_fortalecimento.pdf.

3. Pinheiro OG. Entrevista: uma prática discursiva. In. Spink, MJ. Práticas discursivas e produção de sentidos no cotidiano: aproximações teóricas e metodológicas. Cortez [Internet]. 2013. [acesso em 2019 nov 01]. 156-187. Disponível em:

http://www.bvce.org.br/DownloadArquivo.asp?Arquivo=SPINK_Praticas_discursiv as_e_producao_FINAL_CAPA_NOVAc.pdf.

4. Spink MJP, Frezza RM. Práticas discursivas e produção de sentido: a perspectiva da psicologia social. In. Spink MJ. Práticas discursivas e produção de sentidos no cotidiano: aproximações teóricas e metodológicas. Cortez [Internet]. 2013. [acesso em 2019 nov 01]: 1-21. Disponível em:

http://www.bvce.org.br/DownloadArquivo.asp?Arquivo=SPINK_Praticas_discursiv as_e_producao_FINAL_CAPA_NOVAc.pdf.

5. Spink MJP, Menegon VM. A pesquisa como prática discursiva: superando os horrores metodológicos. In. Spink MJ. Práticas discursivas e produção de sentidos no cotidiano: aproximações teóricas e metodológicas. Cortez [Internet]. 2013. [acesso em 2019 nov 01]: 42-70. Disponível em: http://www.bvce.org.br/DownloadArquivo.asp?Arquivo=SPINK_Praticas_discursiv as_e_producao_FINAL_CAPA_NOVAc.pdf.

6. Morais JL, Souza AM. Significados atribuídos pelo residente recém-ingresso na Residência Multiprofissional em Saúde. Rev. SBPH [Internet]. 2016 Dez [acesso em 2020 out 20]; 19(2): 129-144. Disponível em:

http://pepsic.bvsalud.org/scielo.php?script=sci_arttext\&pid=S151608582016000200009\&Ing=pt.

7. Domingos CM, Nunes EFPA, Carvalho BG. Potencialidades da Residência Multiprofissional em Saúde da Família: o olhar do trabalhador de saúde. Interface (Botucatu) [Internet]. 2015 Dec [acesso em 2020 out 30] ; 19( 55 ): 1221-1232. Disponível em: http://www.scielo.br/scielo.php?script=sci_arttext\&pid=S141432832015000401221\&lng=en. Epub Ago 21, 2015. https://doi.org/10.1590/180757622014.0653. 
8. Maia ÍMQ, Goya N. PERCEPÇÕES DA RESIDÊNCIA MULTIPROFISSIONAL EM SAÚDE DA FAMÍLIA E COMUNIDADE. SANARE-Revista de Políticas Públicas [Internet]. 2016 [acesso em 2020 out 18]; 15(2). Disponível em: https://sanare.emnuvens.com.br/sanare/article/view/1040/586.

9. Filho EJS, Sampaio J, Braga LAV. A avaliação de um programa de residência multiprofissional em Saúde da Família e a comunidade sob o olhar dos residentes. Tempus Actas de Saúde Coletiva [Internet]. 2016 [acesso em 2020 nov 01]; 10(4): 129-149. Disponível em:

https://tempusactas.unb.br/index.php/tempus/article/view/2245.

10. Koetz LCE, Schauren BC. Projeto Pedagógico Programa de Residência Multiprofissional ou em Área Profissional da Saúde. Universidade do Vale do Taquari, Lajeado/RS [Internet]. 2017 [acesso em 2020 out 21]. Disponível em: https://www.univates.br/virtual/pluginfile.php/1321051/mod_resource/content/1/Pro jetoProtocolado251116_oficial.pdf.

11. Brasil CC, Oliveira PRS, Vasconcelos APSM. Perfil e trajetória profissional dos egressos de residência multiprofissional: trabalho e formação em saúde. SANARE-Revista de políticas Públicas [Internet]. 2017 [acesso em 2020 out 07]; 16(1). Disponível em: https://sanare.emnuvens.com.br/sanare/article/viewFile/1095/606.

12. Tutor. In: DICIO, Dicionário Online de Português. Porto: 7Graus [Internet]. 2020 [acesso em 2020 out 23]. Disponível em: https://www.dicio.com.br/tutor/.

13. Brasil. Ministério da Saúde. Portaria n. 1.111/GM, de 5 de julho de 2005: Fixa normas para a implementação e a execução do Programa de Bolsas

14. Botti SHO, Rego S. Preceptor, supervisor, tutor e mentor: quais são seus papéis? Revista Brasileira de Educação Médica [Internet]. 2008 [acesso em 2020 out 30]; 32(3): 363-373. Disponível em:

https://www.scielo.br/scielo.php?pid=S0100-

55022008000300011\&script=sci_arttext\&tlng=pt.

15. Parente JRF. Preceptoria e tutoria na residência multiprofissional em saúde da família. SANARE-Revista de Políticas Públicas [Internet]. 2008 [acesso em 2020 out 30]; 7(2). Disponível em:

https://sanare.emnuvens.com.br/sanare/article/view/31.

16. Cavalcanti IL, Santana JMB. A preceptoria em um programa de residência multiprofissional em oncologia: carências e dificuldades. Gestão e Saúde [Internet]. 2014 [acesso em 2020 out 30]; 5(3): 1045-1054. Disponível em: http://periodicos.unb.br/index.php/rgs/article/download/486/463.

17. Souza SV, Ferreira BJ. Preceptoria: perspectivas e desafios na Residência Multiprofissional em Saúde. ABCS Health Sci [Internet]. 2019 [acesso em 2020 out 30]: 15-21. Disponível em: https://pesquisa.bvsalud.org/portal/resource/pt/biblio-995006. 
18. Silva JC, Contim D, OhI RIB, Chavaglia SRR, Amaral EMS. Percepção dos residentes sobre sua atuação no programa de residência multiprofissional. Acta Paulista de Enfermagem [Internet]. 2015 [acesso em 2020 nov 01]; 28(2): 132138. Disponível em: https://www.scielo.br/scielo.php?pid=S010321002015000200132\&script=sci_abstract\&tIng=pt.

19. Silva RMB, Moreira SNT. Estresse e Residência Multiprofissional em Saúde: Compreendendo Significados no Processo de Formação. Revista Brasileira de Educação Médica [Internet]. 2019 [acesso em 2020 nov 01]; 43(4):157-166. Disponível em: https://www.scielo.br/scielo.php?script=sci_arttext\&pid=S010055022019000400157.

20. Silva LB. Residência Multiprofissional em Saúde no Brasil: alguns aspectos da trajetória histórica. Revista Katálysis [Internet]. 2018 [acesso em 2020 nov 01]; 21(1):200-209. Disponível em: https://www.scielo.br/scielo.php?pid=S141449802018000100200\&script=sci_abstract\&tIng=pt.

21. Dias IMÁV, Pereira AK, Batista SHSS, Casanova IA. A tutoria no processo de ensino-aprendizagem no contexto da formação interprofissional em saúde. Saúde debate [Internet]. 2016 Dec [acesso em 2020 nov 01] ; 40(111): 257-267. Disponível em: http://www.scielo.br/scielo.php?script=sci_arttext\&pid=S0103$11042016000400257 \&$ Ing=en. http://dx.doi.org/10.1590/0103-1104201611120.

22. Casanova IA, Batista NA, Moreno LR. A Educação Interprofissional e a prática compartilhada em programas de residência multiprofissional em Saúde. Interface (Botucatu) [Internet]. 2018 [acesso em 2020 nov 01]; 22(Suppl 1): 1325-1337. Disponível em: http://www.scielo.br/scielo.php?script=sci_arttext\&pid=S141432832018000501325\&Ing=en. Epub July 10, 2018. https://doi.org/10.1590/180757622017.0186.

23. Furtado Juarez Pereira, Oda Wagner Yoshizaki, Borysow Igor da Costa, Kapp Silke. A concepção de território na Saúde Mental. Cad. Saúde Pública [Internet]. 2016 [acesso em 2020 nov 01]; 32(9): e00059116. Disponível em: http://www.scielo.br/scielo.php?script=sci_arttext\&pid=S0102$311 X 2016000902001 \&$ Ing=en. Epub Oct 10, 2016. https://doi.org/10.1590/0102$311 \times 00059116$.

Artigo recebido em: 14/02/2021

Artigo aprovado em: 26/08/2021

Artigo publicado em: 30/08/2021 